\title{
In situ treatment of arsenic contaminated groundwater by aquifer iron coating: Experimental Study
}

Xianjun Xie ${ }^{*^{\mathrm{a}}}$; Yanxin Wang*a ${ }^{\mathrm{a}}$ Kunfu $\mathrm{Pi}^{\mathrm{a}}$; Chongxuan Liu ${ }^{\mathrm{a}, \mathrm{b}} ;$ Junxia $\mathrm{Li}^{\mathrm{a}}$; Yaqing Liu $^{\mathrm{a}}$; Zhiqiang Wang ${ }^{\mathrm{a}}$; Mengyu Duan ${ }^{\mathrm{a}}$

a) State Key Laboratory of Biogeology and Environmental Geology \& School of Environmental Studies, China University of Geosciences, 430074 Wuhan, China b) Pacific Northwest National Laboratory, Richland, WA 99354, USA

*Corresponding author:

Tel: +86-27-67883170; Fax: +86-27-87436235; Email: xjxie@cug.edu.cn (X. Xie) Tel: +86-27-67883998; Fax: +86-27-87481030; Email: yx.wang@cug.edu.cn (Y. Wang)

\begin{abstract}
In situ arsenic removal from groundwater by an aquifer iron coating method has great potential to be a cost effective and simple groundwater remediation technology, especially in rural and remote areas where groundwater is used as the main water source for drinking. The in situ arsenic removal technology was first optimized by simulating arsenic removal in various quartz sand columns under anoxic conditions. The effectiveness was then evaluated in an actual high-arsenic groundwater environment. The arsenic removal mechanism by the coated iron oxide/hydroxide was investigated under different conditions using scanning electron microscopy (SEM)/X-ray absorption spectroscopy, electron probe microanalysis, and Fourier transformation infrared spectroscopy.
\end{abstract}


Aquifer iron coating method was developed via a 4-step alternating injection of oxidant, iron salt and oxygen-free water. A continuous injection of $5.0 \mathrm{mmol} / \mathrm{L} \mathrm{FeSO}_{4}$ and $2.5 \mathrm{mmol} / \mathrm{L} \mathrm{NaClO}$ for 96 hours can form a uniform goethite coating on the surface of quartz sand without causing clogging. At a flow rate of $7.2 \mathrm{~mL} / \mathrm{min}$ of the injection reagents, arsenic (as $\mathrm{Na}_{2} \mathrm{HAsO}_{4}$ ) and tracer fluorescein sodium to pass through the iron-coated quartz sand column was approximately at 126 and 7 column pore volumes, respectively. The retardation factor of arsenic was 23.0, and the adsorption capacity was $0.11 \mathrm{~mol}$ As per mol Fe. In situ arsenic removal from groundwater in an aquifer was achieved by simultaneous injections of $\mathrm{As}(\mathrm{V})$ and $\mathrm{Fe}(\mathrm{II})$ reagents. Arsenic fixation resulted from a process of adsorption/co-precipitation with fine goethite particles by way of bidentate binuclear complexes. Therefore, the study results indicate that the high arsenic removal efficiency of the in situ aquifer iron coating technology likely resulted from the expanded specific surface area of the small goethite particles, which enhanced arsenic sorption capability and/or from co-precipitation of arsenic on the surface of goethite particles.

Keywords: Groundwater; Arsenic contamination; Iron coating; In situ immobilization

\section{Introduction}

Arsenic in aquifer sediments can be released into groundwater under various hydrogeological and geochemical conditions, causing abnormal elevated arsenic concentrations (Nordstrom, 2002). Long-term consumption of groundwater containing high concentration of arsenic can cause various human health problems, including skin cancer, lung cancer, liver and kidney diseases (Duker et al., 2005). The World Health Organization (WHO) has set the limit of arsenic in drinking water at 10 
$\mu \mathrm{g} / \mathrm{L}$ (WHO, 2011). High arsenic groundwater occurs widely around the world, and millions of people from more than 70 regions are suffering from arsenic exposure in varying degrees, especially those living in India, Bangladesh, Vietnam, Burma, Chile, Argentina, Hungary, the United States and China (Nordstrom, 2002; Smedley and Kinniburgh, 2002). In China, high arsenic groundwater has been observed in Datong basin of Shanxi Province, Hetao basin of Inner Mongolia and in Xinjiang and Taiwan Provinces where approximately 18.5 million people are at risk exposing to high arsenic groundwater. The groundwater arsenic level reaches a magnitude of $\mathrm{mg} / \mathrm{L}$ (Guo et al., 2014; Xie et al., 2009; Xie et al., 2008).

To remove arsenic from groundwater, various remediation technologies have been developed that can be largely divided into two categories: pump and treatment and in situ remediation. Pump and treatment technologies have been extensively investigated and applied commercially (Ravenscroft et al., 2009). The treatment technologies primarily include co-flocculation/precipitation (Bordoloi et al., 2013), ion exchange (Korngold et al., 2001), membrane separation (Shih, 2005), lime softening (EPA, 2000), active adsorption (Mishra and Farrell, 2005), redox process (Lee et al., 2003) and biological treatment (Keimowitz et al., 2007). Most of these methods are effective at removing arsenic from groundwater and are able to decrease arsenic concentration from several hundred $\mu \mathrm{g} / \mathrm{L}$ to $10 \mu \mathrm{g} / \mathrm{L}$ or less. However, these technologies have shortcomings, such as long processing times, complex operations, high operating costs, difficult pre-treatment conditions, and secondary pollution generation (Mondal et al., 2013; Mohan and Pittman, 2007; Mondal et al., 2006). It is very difficult to promote and apply the pump and treatment technologies in remote and rural areas because local communities cannot afford the high costs of the water treatment systems and routine maintenance, as well as lack knowledge in operating 
complex procedures. In contrast, in situ remediation methods have some distinct advantages over pump and treatment methods (Shan et al., 2013; van Halem et al., 2010), including the following:

(1) Pricey processing materials are not required, and maintenance costs are low;

(2) The in situ treated groundwater can be used directly or after simple treatment, and no extra investment in equipment is needed;

(3) Operation and maintenance are simple and suitable for remote and undeveloped rural areas.

The basic principle of in situ remediation is that oxidants (e.g., sodium hypochlorite) are periodically injected into the iron-rich aquifers via an injection well (Welch et al., 2008). In the case the aquifer materials contain low ferrous iron, a joint injection of oxidant and ferrous iron is required (Miller, 2006). When the oxidant and ferrous solutions are injected into an anoxic aquifer, ferric hydroxides are formed on the surface of the matrix particles through the heterogeneous ferrous iron oxidation reaction. Because the ferric hydroxide particles in the aquifer sediments have a large surface area, they play the dominant role in the removal of arsenic from the groundwater (Richmond et al., 2004). It is worth noting that during this process, ferrous iron can also be adsorbed and subsequently oxidized to form new ferric hydroxide particles, which can further adsorb ferrous iron and arsenic. Taking the oxidant of $\mathrm{ClO}^{-}$as an example, the process can be briefly described as follows:

$$
\begin{aligned}
& 2 \mathrm{Fe}^{2+}+\mathrm{ClO}^{-}+4 \mathrm{OH}^{-} \rightarrow 2 \mathrm{Fe}^{3+} \mathrm{OOH}_{(s)}+\mathrm{Cl}^{-}+\mathrm{H}_{2} \mathrm{O} \\
& \mathrm{Fe}^{3+} \mathrm{OOH}_{(s)}+\mathrm{Fe}^{2+}+\mathrm{H}_{2} \mathrm{O} \rightarrow \mathrm{Fe}^{3+} \mathrm{OOFe}^{2+} \mathrm{OH}_{(s)}+2 \mathrm{H}^{+} \\
& \mathrm{Fe}^{3+} \mathrm{OOFe}^{2+} \mathrm{OH}_{(s)}+0.5 \mathrm{ClO}^{-}+2 \mathrm{OH}^{-} \rightarrow 2 \mathrm{Fe}^{3+} \mathrm{OOH}_{(s)}+0.5 \mathrm{Cl}^{-}+0.5 \mathrm{H}_{2} \mathrm{O}
\end{aligned}
$$

$$
\mathrm{Fe}^{3+} \mathrm{OOH}_{(s)}+\mathrm{H}_{2} \mathrm{AsO}_{4}^{2-} \rightarrow \mathrm{Fe}^{3+} \mathrm{OH}_{2} \mathrm{AsO}_{4(s)}+\mathrm{OH}^{-}
$$


The in situ removal of iron from groundwater has been reported in Central Europe and the United States (Appelo et al., 1999; Mettler and Von Gunten, 2002). In contrast, the in situ arsenic removal is a relatively new venture (Rott et al., 2002; van Halem et al., 2009). Nevertheless, the in situ arsenic removal has potentially been developed as a cost-effective method to provide safe drinking water for rural and remote areas. It has been reported that injecting aerated water into an aquifer reduced the concentration of arsenic from as high as $400 \mu \mathrm{g} / \mathrm{L}$ to the WHO standard $(\leq 10$ $\mu \mathrm{g} / \mathrm{L}$ ) (Appelo and de Vet, 2003; Rott et al., 2002). In Bangladesh, Sarkar and Rahman (2001) reported that using this method can lower high concentrations of arsenic $(500-1300 \mu \mathrm{g} / \mathrm{L})$ by more than $50 \%$. While simultaneously injecting aerated water and ferrous iron into groundwater, the $\mathrm{As}(\mathrm{V})$ concentration was reduced from $100 \mu \mathrm{g} / \mathrm{L}$ to a level lower than the WHO standard (Miller, 2006). However, this is not a cost-effective method because large volumes of aerated water were required to inject into the target aquifer.

In Datong basin of China, high arsenic groundwater occurs widely and the groundwater is weakly alkaline and reducing, and contains low $\mathrm{Fe}(\mathrm{II})$ concentration $(<1 \mathrm{mg} / \mathrm{L})$ and very low dissolved oxygen content $(<0.01 \mathrm{mg} / \mathrm{L})(\mathrm{Xie}$ et al., 2008). Because the groundwater in this area is an important water resource for drinking, there is an urgent need to develop a cost-effective groundwater remediation method to eliminate the risk of exposure to arsenic. In this study, $\mathrm{FeSO}_{4}$ and $\mathrm{NaClO}$ were used as injection reagents in an anaerobic column system to develop an in situ arsenic treatment technology by aquifer iron coating and to evaluate the applicability of this technology to the high arsenic region in Datong basin. Therefore, the objectives of this study include the determination of the optimal concentrations and loading time of 
the $\mathrm{NaClO}$ and $\mathrm{FeSO}_{4}$, the arsenic removal effectiveness of the iron oxide/hydroxide coating and its mechanism of arsenic immobilization.

\section{Materials and methods}

\subsection{Preparation of the arsenic-removing materials}

The columns used in this study had a length of $30.0 \mathrm{~cm}(\mathrm{~L})$, an inner diameter (ID) of $4.5 \mathrm{~cm}$ and a volume (V) of $477 \mathrm{~cm}^{3}$. The columns (made of glass material) and required accessories (e.g., tubing, seals) were submerged in diluted $\mathrm{HCl}$ (15\% $\mathrm{m} / \mathrm{V}$ ) for 48 hours $(\mathrm{h})$, rinsed with deionized water and then air-dried. Quartz sand (with a particle diameter of $0.30-0.84 \mathrm{~mm}$ ) was used to mimic the aquifer sediments. The sand was soaked in $\mathrm{HCl}(6 \mathrm{~mol} / \mathrm{L})$ for $24 \mathrm{~h}$, rinsed repeatedly with deionized water before use, and then stored in oxygen-free deionized water.

The wet packing procedure was adopted to fill the columns. The experimental column was first filled with oxygen-free deionized water followed by the slow addition of the prepared quartz sand and then sealed for future use. During this process, the column was filled with water and ensured to be air-free so that the quartz sand was packed uniformly, well-mixed and oxygen-free. Meanwhile, blank columns were similarly prepared using this procedure.

The in situ injection process was simulated under strictly anaerobic condition. In order to maintain an anaerobic condition, all experiments were operated in a chamber with $\mathrm{N}_{2}$ atmosphere. A 4-step alternating injection method was adopted to inject the $\mathrm{FeSO}_{4}$ solution, the oxygen-free deionized water and the $\mathrm{NaClO}$ solution into the columns. Once the $\mathrm{NaClO}$ oxidized $\mathrm{Fe}(\mathrm{II})$, a coating of iron oxide/hydroxide formed on the surface of the quartz sand. The flow rate was controlled using multi-channel pumps equipped with high-strength PVC tubing. 
To avoid clogging by the large amount of precipitates near the inlet opening, oxygen-free deionized water was used to flush the column between the injections of $\mathrm{FeSO}_{4}$ and $\mathrm{NaClO}$ solutions, which ensured the uniform diffusion of $\mathrm{FeSO}_{4}$ and $\mathrm{NaClO}$ in the column and the formation of a homogeneous iron oxide/hydroxide coating on the surface of the quartz sand. A schematic figure illustrating column preparation is shown in Figure 1. Briefly, the procedure was as follows:

Step 1: $\mathrm{FeSO}_{4}$ solution $(5.0 \mathrm{mmol} / \mathrm{L})$ was loaded into the column at a flow rate of $12.1 \mathrm{~mL} / \mathrm{min}$ for $1.0 \mathrm{~min}$ under anaerobic conditions.

Step 2: Oxygen-free deionized water was loaded at the same flow rate for 1.0 $\min$.

Step 3: $\mathrm{NaClO}$ solution $(2.5 \mathrm{mmol} / \mathrm{L})$ was loaded for $1.2 \mathrm{~min}$, which was a slight overload based on the stoichiometric balance to ensure sufficient oxidation of Fe (II) by the $\mathrm{NaClO}$ solution to form the iron oxide/hydroxide.

Step 4: Oxygen-free deionized water was again injected for $1.0 \mathrm{~min}$ at a flow rate of $12.1 \mathrm{~mL} / \mathrm{min}$.

The above procedures were repeated until the color of quartz sand in the column showed no significant change.

\subsection{Optimization of the loading time}

Using the above described preparation method, $\mathrm{FeSO}_{4}$ solution $(5.0 \mathrm{mmol} / \mathrm{L})$ and $\mathrm{NaClO}$ solution $(2.5 \mathrm{mmol} / \mathrm{L})$ were used to investigate the change in color of the column (column I) with the loading time to determine the optimal loading time.

Four columns were prepared, and the concentration of $\mathrm{FeSO}_{4}$ solution was set to $0,2.0,3.0$, and $5.0 \mathrm{mmol} / \mathrm{L}$ and that of $\mathrm{NaClO}$ was set to $0,1.0,1.5$, and $2.5 \mathrm{mmol} / \mathrm{L}$. Use the same injection procedure and injection time, the change in color of the 
columns was observed to determine the optimal concentration of the injection solutions. The columns were sequentially labeled as columns II-a, II-b, II-c and II-d.

\subsection{Arsenic removal experiments}

Fluorescein sodium was used as a tracer reagent to compare the retardation of arsenic breakthrough. Column I was flushed with 10 column pore volumes of oxygen-free deionized water, and fluorescein sodium solution $(94.90 \mathrm{mg} / \mathrm{L})$ was then continuously pumped into the column at a flow rate of $7.2 \mathrm{~mL} / \mathrm{min}$. During loading, $10 \mathrm{~mL}$ effluent samples were collected with an autosampler at a 30 second interval, and the concentration of fluorescein sodium in each of the effluent sample was immediately analyzed. In this study, a total of approximately 12 column pore volumes of fluorescein sodium solution were injected and a total of 355 samples were collected for fluorescein sodium concentration measurement.

$\mathrm{Na}_{2} \mathrm{HAsO}_{4}$ was used to simulate the arsenic in groundwater. The arsenic removal efficiency by the prepared arsenic removal material was evaluated by $\mathrm{Na}_{2} \mathrm{HAsO}_{4}$ transport experiment. By comparing the breakthrough curves of the fluorescein sodium and $\mathrm{Na}_{2} \mathrm{HAsO}_{4}$ solutions, the arsenic removal efficiency of the material was assessed, and the arsenic removal capacity was calculated based on the iron and arsenic content in the coating. The arsenic removal procedures were described as follows:

Step 1: Column I was continuously flushed with 10 column pore volumes of oxygen-free deionized water at a flow rate of $7.2 \mathrm{~mL} / \mathrm{min}$.

Step 2: The $\mathrm{Na}_{2} \mathrm{HAsO}_{4}$ solution $(3000 \mu \mathrm{g} / \mathrm{L} \mathrm{As}(\mathrm{V}))$ was injected into Column I at the same flow rate, and $10 \mathrm{~mL}$ effluent solutions were collected every 1-2 hour with an autosampler. Purified $\mathrm{HCl}$ was added to each of the effluent samples to acidify 
them to $\mathrm{pH}<2$. The acidified effluent samples were then stored at $4{ }^{\circ} \mathrm{C}$ in the dark, and arsenic concentrations were measured within $72 \mathrm{~h}$.

Step 3: Once the arsenic concentrations in the loading solution and the effluent samples were equal and kept constant for $24 \mathrm{~h}$, the injection solution was switched to oxygen-free deionized water. A total of 60 samples for arsenic concentration determination were collected.

The column prepared with iron-coated quartz sand and saturated with arsenic was labeled Column III and stored in the dark for future use.

The quartz sand from Column III was carefully collected in a beaker, and 500 $\mathrm{mL}$ of $6 \mathrm{~mol} / \mathrm{L} \mathrm{HCl}$ solution was added. The column was then placed on a shaker at room temperature, and the solution was harvested after $12 \mathrm{~h}$ of incubation. This procedure was repeated until there was no visible brown residue on the surface of quartz sand. Finally, the quartz sand was rinsed three times using deionized water, and the rinse solutions were decanted and diluted to $2 \mathrm{~L}$ with deionized water. The concentrations of iron and arsenic were determined and then were used to calculate arsenic removal capacity.

\subsection{The simulation of in situ arsenic removal from groundwater with the iron coating}

The blank quartz sand column was prepared according to the procedures described above. To simulate real groundwater environment and in situ remediation process, $\mathrm{FeSO}_{4}$ solution was replaced with a $\mathrm{Fe}(\mathrm{II})$ and $\mathrm{As}(\mathrm{V})$ mixture solutions at concentrations of $5.0 \mathrm{mmol} / \mathrm{L}$ and $233 \mu \mathrm{g} / \mathrm{L}(3.1 \mu \mathrm{mol} / \mathrm{L})$ (the average arsenic content in Datong groundwater), respectively. The experimental devices were placed in oxygen-free deionized water to prevent oxygen exposure. Using the 4-step alternating 
injection method described in section 2.1, the Fe(II) and As(V) mixture, deionized water, oxygen-free $\mathrm{NaClO}$ solution, and deionized water were alternately loaded into the blank quartz sand column at a flow rate of $12.1 \mathrm{~mL} / \mathrm{min}$. Effluent samples were collected at a 5-10 min interval using an autosampler and stored at $4{ }^{\circ} \mathrm{C}$ for analysis. The in situ arsenic removal simulation took approximately $96 \mathrm{~h}$, and a total of 1100 samples were collected for arsenic concentration determination. The column used in this experiment was labeled Column IV.

After the completion of the experiment, the iron-coated quartz sand was collected from the column and processed as described in section 2.3. The concentrations of iron and arsenic and the amount of adsorbed arsenic concentrations were then determined.

\subsection{Chemical Analysis}

The concentration of fluorescein sodium and iron in the collected samples were measured using a portable spectrophotometer (HACH, DR2800). The arsenic concentration in the solutions was determined using an atomic fluorescence spectrometer (AFS, Beijing Haitian Instruments). The phenanthroline method was used to determine the iron concentration after the iron was reduced to $\mathrm{Fe}(\mathrm{II})$ by the reducing agent (hydroxylamine hydrochloride, $10 \mathrm{wt} \%$ ). The detection limit of spectrophotometer for both fluorescein sodium and ferrous ion concentration analysis were $0.01 \mathrm{mg} / \mathrm{L}$ and the atomic fluorescence spectrometer for arsenic concentration determination was $0.1 \mu \mathrm{g} / \mathrm{L}$. The standards and replicates were measured in every ten samples as an analysis routine for arsenic, fluorescein sodium and ferrous ion concentration determination. Unless otherwise stated, the reproducibility was better than $5 \%$ relative for all compounds analyzed. 
A total of $10.00 \mathrm{~g}$ of iron-coated quartz sand was taken from Columns I, III and IV, air-dried, and stored in a vacuum in the dark. The iron-coated quartz sand particles were selected and treated with gold coating, and the morphology of the coating layer on the surface of the quartz sand was observed using an ultra-high resolution field emission scanning electron microscope (Hitachi, SU8010). The chemical composition and the element content of the target area were determined using X-ray energy dispersive spectroscopy (Ametek, EDAX APPOLLO XP). Several quartz sand particles with intact surfaces were selected and inlayed with epoxy resin and then polished. They were then subjected to an electron probe for microanalyzer (Japan Electronics Co., JXA-8230) equipped with an X-ray microanalysis system (Oxford Company, Inca X-Act) to analyze the microstructure and mineral composition of the iron coating. The accuracy and precision of SEM-EDS and EPMA-EDS for iron coating analysis were evaluated by repeated analysis of two laboratory reference standards Arsenoprite and Chalcopyrite. Quantified values (wt \%) were within $10 \%$ of accepted values for major and minor elements, and reproducibility was better than $8 \%$ relative for all compounds analyzed. Additionally, $5.00 \mathrm{~g}$ of the sample particles were mixed with $5.00 \mathrm{~g}$ of pure solid $\mathrm{KBr}$, ground to powder in an agate mortar and passed through a 100-mesh sieve. The forms of arsenic and iron bound to the mineral surface were analyzed using a Fourier transformation infrared spectrometer (Thermo-Fisher, Nicolet6700) with the $\mathrm{KBr}$ powder as the background control. The preparation of $\mathrm{KBr}$ pellets relied on a standardized procedure to enhance reproducibility. IR spectra of powered samples were recorded from the $4000 \mathrm{~cm}^{-1}$ to $400 \mathrm{~cm}^{-1}$ and the IR spectra were obtained at a resolution of $0.6 \mathrm{~cm}^{-1}$. 
After the column was completely filled with water, the water was gravity-drained from the column and collected. The collected water $\left(m_{\mathrm{p}}\right)$ was then weighed using a balance. The $m_{p}$ was measured repeatedly, and the mean of the measurements was used to calculate the column pore volume $\left(V_{p}\right)$, and the porosity $(\eta)$ of the quartz sand filled column.

$$
\eta=\frac{m_{\mathrm{p}}}{\rho_{\text {water }} \times V_{\mathrm{p}}} \times 100 \%
$$

The delayed breakthrough of the arsenic in the column relative to the inert fluorescein sodium tracer was represented by the dimensionless retardation factor $(R)$ (van Halem et al., 2010), which can be calculated as follows:

$$
R_{A S}=\frac{\left(\frac{V}{V_{i}}\right)_{A s} \frac{C}{\bar{C}_{0}}=0.5}{\left(\frac{V}{V_{i}}\right)_{\operatorname{tracer} \frac{C}{C_{0}}}=0.5}
$$

where $C$ is the measured value; $C_{0}$ is the initial value of the injection solution, and the inert tracer is fluorescein sodium. The $V / V_{\mathrm{i}}$ value equals the water volume $(V)$ divided by the column pore volume $\left(V_{i}\right)$.

\section{Results and discussion}

\subsection{Optimal conditions for iron coating}

The concentration of the injected solution can directly affect the performance of arsenic removal materials by affecting their removal capacity and arsenic removal time. However, the column is prone to blockage with injection high concentrations of $\mathrm{FeSO}_{4}$ and $\mathrm{NaClO}$ solutions. While the preparation time of the arsenic removal material is significantly prolonged using low concentrations of these solutions. Therefore, selecting the optimal concentrations of the injection reagents plays a vital role to in situ groundwater arsenic immobilization. In addition, the change in porosity 
of the aquifer has a direct impact on the implementation of arsenic removal technologies by affecting the transport of reagents and residence time of As-removal material interactions. If the injected $\mathrm{NaClO}$ and $\mathrm{FeSO}_{4}$ solutions form excessive precipitates on the surface of the sediment particles, which can lead to a significant decrease in porosity and the permeability of the aquifer materials, then the method will not be able to efficiently remove arsenic in groundwater. Therefore, in this study, the optimal loading time for the formation of iron coating materials, the optimal concentration of the injection solutions, and the resultant changes in porosity were investigated using the column system to provide important insights into the practice of in situ arsenic removal.

\subsubsection{Optimal loading time}

The brown color of the coating materials on the surface of quartz sand in Column I gradually darkened over time (SFig. 1). The coloration was relatively uniform in the column at different times, indicating that the iron coating homogeneously formed during injection. The color of the coating materials showed no change, and the Fe content in the outflow water did not decrease significantly after $96 \mathrm{~h}$ of loading. In addition, no significant changes in flow rate and injection pressure were observed during the reagent injection process, indicating that no clogging occurred in the column during injection. Consequently, $96 \mathrm{~h}$ was set as the optimal loading time for this system.

\subsubsection{Optimal injection concentrations of $\mathrm{FeSO}_{4}$ and $\mathrm{NaClO}$}

SFig. 2 depicts the iron coating effectiveness of the columns (Columns II-a, -b, $-c$ and $-d$ ) injected with four different injection reagents concentrations. When the 
concentrations of $\mathrm{FeSO}_{4}$ and $\mathrm{NaClO}$ were too low (e.g., when $\mathrm{FeSO}_{4}$ and $\mathrm{NaClO}$ concentrations were $2.0 \mathrm{mmol} / \mathrm{L}$ and $1.0 \mathrm{mmol} / \mathrm{L}$, respectively), the color of the surface of quartz sand at the bottom of the column was light and did not change much even significantly increased in loading time. When $\mathrm{NaClO}$ and $\mathrm{FeSO}_{4}$ concentrations were increased to $5.0 \mathrm{mmol} / \mathrm{L}$ and $2.5 \mathrm{mmol} / \mathrm{L}$, respectively, the color of the column sand materials darkened and was also more uniform, indicating that the loaded amount of iron oxide/hydroxide was higher and the distribution of the precipitates in the column was more even, both of which being beneficial to arsenic removal. Moreover, the loading process using $5.0 \mathrm{mmol} / \mathrm{L} \mathrm{FeSO}_{4}$ and $2.5 \mathrm{mmol} / \mathrm{L} \mathrm{NaClO}$ injection solutions only slightly changed the porosity of the columns $(<0.1 \%)$. The initial porosity is $\eta=25.24 \%$. The optimal concentrations of $\mathrm{FeSO}_{4}$ and $\mathrm{NaClO}$ were consequently set at $5.0 \mathrm{mmol} / \mathrm{L}$ and $2.5 \mathrm{mmol} / \mathrm{L}$, respectively, in this study.

\subsection{Arsenic removal via iron-coated quartz sand}

\subsubsection{The efficacy of arsenic removal}

The breakthrough curves of fluorescein sodium and $\mathrm{HAsO}_{4}{ }^{2-}$ in the iron-coated quartz sand column (Column I) behaved differently (Fig. 2). When the solution injection velocity $\left(v_{j}\right)$ was $7.2 \mathrm{~mL} / \mathrm{min}$, the breakthrough of fluorescein sodium started at approximate $1.2 \mathrm{Vp}$, and the complete breakthrough was at approximate $7 \mathrm{Vp}$. Arsenic started breakthrough at approximate $93.3 V_{p}$ that means approximately $11.2 \mathrm{~L}$ of high arsenic groundwater (with the $\mathrm{As}(\mathrm{V})$ concentration of $3000 \mu \mathrm{g} / \mathrm{L}$ ) was treated with the effluent arsenic concentration lower than the WHO standard level of $10 \mu \mathrm{g} / \mathrm{L}$. The complete breakthrough for arsenic was approximately $126 V_{p}$. This result indicated that the transport of arsenic was retarded significantly, and the retardation factor of arsenic $\left(R_{A s}\right)$ was 23.0. Under controlled conditions, the heterogeneous 
oxidation and adsorption process of $\mathrm{Fe}(\mathrm{II})$ was dominant inside the column, and the arsenic removal occurred through adsorption on the surface of iron oxide/hydroxide, which led to the significant retardation of arsenic (Rott and Friedle, 1985).

Through the analysis of solid phase iron and arsenic contents, it can be seen that the amount of coated iron in the column was $0.4240 \mathrm{~g}$, and the adsorbed total arsenic was $64.30 \mathrm{mg}$. This means that when the groundwater flow rate was $7.2 \mathrm{~mL} / \mathrm{min}$, the dynamic saturation adsorption ratio of arsenic was $151.7 \mathrm{mg} \mathrm{As} / \mathrm{g} \mathrm{Fe}$, or $0.11 \mathrm{~mol}$ As/mol Fe. Raven et al. (1998) showed that between pH 4.6 and 9.2, the maximum absorption capacity of $\mathrm{As}(\mathrm{V})$ on ferrihydrite reach up to $0.25 \mathrm{~mol} \mathrm{As} / \mathrm{mol} \mathrm{Fe}$ and 0.16 mol As/mol Fe, respectively, the values that are higher than the arsenic dynamic saturation adsorption ratio observed in this study. This is most likely because, relative to static adsorption, the arsenic dynamic adsorption driven by the water flow did not reach equilibrium.

\subsubsection{The arsenic fixation mechanism of the iron coating}

SEM analysis (Fig. 3a) shows that after coating material formation, the surface of quartz sand was covered by a layer of scaly crystalline minerals. The high iron content indicates that the mineral was iron-bearing mineral, which was inferred to be the goethite $(\alpha-\mathrm{FeOOH})$ based on its typical scaly morphology (Cornell and Schwertmann, 2003). Goethite is a common crystalline iron mineral in nature that can be generated by amorphous iron precipitates originating from the oxidation of ferrous iron through the aging process, and it has good arsenic adsorption capability (Dixit and Hering, 2003). By comparing the morphologies of the crystallized iron mineral phases before and after arsenic adsorption (Fig. 3), it can be seen that the morphology of the crystallized iron mineral did not change remarkably after arsenic adsorption and 
still presented the scaly crystal morphology. However, the EDS energy spectrum result indicates that arsenic content increased significantly from below the detection limit to $1.1 \mathrm{wt} \%$ (EDS, Fig. 3) and $2.6 \mathrm{wt} \%$ (EPMA, Fig. 4), respectively, after adsorption. This result confirmed that the removed arsenic was bound to the surface of iron mineral, most likely due to the adsorption of arsenic by goethite $(\alpha-\mathrm{FeOOH})$. Goethite can use a portion of the octahedral channel to bond with hydrogen. This thereby doubles the amount of edges and corners and thus creates twice the amount of octahedral $\mathrm{FeO}-\mathrm{OH}$ bonds, which represent an important type of iron oxide/hydroxide reaction surfaces that can adsorb the contacting oxyanions, e.g., arsenate, through ligand complexation (Giles et al., 2011). Zhao and Stanforth (2001) also revealed that the surface of goethite has a large number of active adsorption sites and high adsorption capacity for high concentrations of arsenic, which could thereby significantly delay the breakthrough of arsenic in the column and result in excellent arsenic removal.

IR spectra permit to determine the local coordination environments of As (III) and $\mathrm{As}(\mathrm{V})$ sorbed onto the iron oxide/hydroxides. The coating layer of Column I (before arsenic adsorption) and Column III (after saturated arsenic adsorption) were therefore analyzed using IR spectroscopy, and the results are shown in Figure 5. In general, the surface groups of the iron oxide/hydroxide were mainly $-\mathrm{OH}$, as shown in Figure 6a. The loaded arsenic has three ways to bind to iron oxide/hydroxide, as depicted in Figure 6b, which can be tested by examining the changes in the arsenic group and hydroxyl group vibrations signal (Wang and Mulligan, 2008). From Figure 5, the IR spectra after arsenic adsorption showed that, except from the enhanced absorption peaks at $1618 \mathrm{~cm}^{-1}$ and $785 \mathrm{~cm}^{-1}$ that stemmed from the As-O stretching vibration of the $\mathrm{As}(\mathrm{V})$ entity, there was another distinct absorption peak at $3440 \mathrm{~cm}^{-1}$ 
that corresponded to the vibration absorption peak of $v(\mathrm{OH})$ derived from the As-OH bond (after eliminating the interference of water molecules) (Voegelin and Hug, 2003). The relatively broad absorption peak of $3440 \mathrm{~cm}^{-1}$ suggests that the bonded interaction of $-\mathrm{OH}$ was relatively loose, thereby inferring that the adsorption of arsenic on the iron minerals could be the first type of complex depicted in Figure $6 \mathrm{~b}$, via a monodentate mononuclear complex (Sun and Doner, 1996; Wang and Mulligan, 2008). This type of complex can enhance the vibration of Fe-O bond and lead to enhance absorption peak of Fe-O bond at $1086 \mathrm{~cm}^{-1}$ and the shoulder at $1174 \mathrm{~cm}^{-1}$. Moreover, the IR spectra after arsenic adsorption exhibited significantly intensified absorption peaks at $1618 \mathrm{~cm}^{-1}, 1793 \mathrm{~cm}^{-1}$ and $1886 \mathrm{~cm}^{-1}$ (Fig. 5), which resulted from the formation of As-O-Fe (Voegelin and Hug, 2003). The enhanced absorption peak at $692 \mathrm{~cm}^{-1}$ was due to the presence of $v(\mathrm{As}-\mathrm{OH})$ vibration, which significantly enhanced the absorption of the $-\mathrm{OH}$ groups. These results demonstrate that arsenic complexes were formed via the hydroxyl groups at the iron oxide surface, which was consistent with the result obtained by the coordination structure analysis of $\mathrm{As}(\mathrm{V})$ on the surface of goethite using extended X-ray absorption fine structure (EXAFS) spectroscopy (Loring et al., 2009), in which the arsenic adsorption on the surface of goethite was mainly through a way of monodentate mononuclear complex. Grossl et al. (1997) also found that $\mathrm{As}(\mathrm{V})$ first formed the monodentate inner spherical complexes with a high adsorption rate and then gradually formed the bidentate inner spherical complexes with a lower adsorption rate through ligand exchange.

Therefore, during the experiment, Fe(II) was rapidly oxidized to form iron oxide/hydroxide (Taylor and Konhauser, 2011; Bligh and Waite, 2011) and precipitated on the surface of the quartz sand, which might have gradually transformed into crystalline iron mineral phase (Bligh and Waite, 2011) mainly 
consisting of goethite. The arsenic bound to goethite have formed monodentate mononuclear complexes on the surface of goethite, where abundant adsorption sites prompted the absorption of a large amount of arsenic, resulting in a significant lag in arsenic breakthrough and arsenic removal from the aqueous phase.

\subsection{Simulation of in situ arsenic and iron removal from groundwater}

\subsubsection{The efficacy of arsenic removal}

The arsenic content in the all effluents of Column IV was always below the detection limit $(0.1 \mu \mathrm{g} / \mathrm{L})$, indicating that the arsenic in the groundwater was completely removed during the experiment. Therefore, the objective of simultaneous removal of arsenic and iron in situ was achieved. Arsenic breakthrough in the column did not occur, so the arsenic retardation factor was not analyzed during this process. Due to the simultaneous injection of $\mathrm{Fe}(\mathrm{II})$ and $\mathrm{As}(\mathrm{V})$, iron oxide/hydroxide formed through the oxidation of $\mathrm{Fe}(\mathrm{II})$, at the same time arsenic in the aqueous phase might have been eliminated through adsorption or co-precipitation with iron oxide/hydroxide (Tokoro et al., 2010).

During this experiment, the total amount of iron coating in Column IV was 0.32 $\mathrm{g}$, and the adsorbed total arsenic was $22.6 \mathrm{mg}$; both were lower than that of Column III. The amount of arsenic adsorption was $0.05 \mathrm{~mol} \mathrm{As} / \mathrm{mol} \mathrm{Fe}$, which was much lower than the dynamic saturation adsorption ratio in Column III $(0.11 \mathrm{~mol} \mathrm{As} / \mathrm{mol}$ $\mathrm{Fe})$. The simultaneous injection of $\mathrm{Fe}(\mathrm{II})$ and $\mathrm{As}(\mathrm{V})$ reduced the amounts of loaded iron, indicating that arsenic might affect the oxidation and/or precipitation of iron and might lead to reduced iron oxide/hydroxide yield (Jiang et al., 2013). During the precipitation of iron oxide/hydroxide, the adsorption of arsenic onto the primary Fe-bearing minerals crystallites retards crystal growth and coagulation by preventing 
further Fe-O-Fe-polymerization (Regenspurg and Peiffer, 2005). The inhibition of iron mineral crystal growth results in a decreased mean crystallite size and an enlarged surface area (Dixit and Hering, 2003), which can significantly enhance arsenic absorption capability. It is noteworthy that the breakthrough of arsenic was not observed until the end of this experiment in this study, which means that arsenic adsorption did not reach saturation. This observation may be due to the formation of small scaly goethite particles (Fig. 7c) during simultaneous injection of $\mathrm{Fe}(\mathrm{II})$ and As $(V)$. Therefore, arsenic adsorption could have continued, and more arsenic could have been removed. This is an important finding for the implementation of arsenic removal practices because the in situ iron coating technology is likely to result in improved arsenic removal efficiency and long life when applied in a high-arsenic aquifer.

\subsubsection{Mechanism of arsenic removal}

By comparing the SEM morphologies of the coating layers of Columns III and IV (Fig. 7), it can be seen that simultaneously injected $\mathrm{As}(\mathrm{V})$ and $\mathrm{Fe}(\mathrm{II})$ into the column formed much smaller goethite crystal on the surface of quartz sand (Fig. 7c). In light of the EDS energy spectrum (Fig. 7), high contents of both arsenic and iron can be detected in the iron coating with the values of $3.1 \mathrm{wt} \%$ and $12.3 \mathrm{wt} \%$, respectively. Both the SEM and EDS results confirm that the newly formed iron oxide/hydroxide was likely dominated by the small goethite crystal particles, and arsenic was fixed at the same time. Newly formed small iron oxide/hydroxide particles usually have high (adsorption) surface areas (Cornell and Schwertmann, 2003) that can facilitate arsenic removal. The apparent differences in the iron mineral phases of Column III and IV suggest that arsenic is likely involved in iron oxidation 
and Fe-bearing mineral formation during simultaneous injection $\mathrm{As}(\mathrm{V})$ and $\mathrm{Fe}(\mathrm{II})$. During the iron mineral formation, two types of interactions might exist between arsenic and iron: (1) As in the case of Column III, Fe(II) was oxidized to form iron mineral phase and was loaded on the surface of quartz sand particles and then adsorbs arsenic. (2) Arsenic joins in the reaction while Fe(II) oxidizes and precipitates, so arsenic and iron co-precipitate and result in the formation of small goethite crystal particles due to the involvement of arsenic (Dixit and Hering, 2003; Jiang et al., 2013). The significant differences between the iron mineral phases shown in Column III and IV indicate that the simulated in situ groundwater arsenic removal process most likely followed the second process as the main binding mechanism.

The results of IR spectra (Fig. 8) showed that, relative to Columns I and III, Column IV had a significantly weakened absorption peak at $1086 \mathrm{~cm}^{-1}$ and the shoulder of $1174 \mathrm{~cm}^{-1}$, which was possibly due to arsenic being bonded to the adjacent pair of -O-Fe that hindered the vibration of the Fe-O bond (Carabante et al., 2009). In addition, weaker absorbance at peaks of $1618 \mathrm{~cm}^{-1}$ and $785 \mathrm{~cm}^{-1}$ indicated As $(V)$ adsorption on the iron oxide surfaces was probably affected by the co-precipitation process which changed either the amount of adsorbed $\operatorname{As}(\mathrm{V})$ or the strength of the formed surface complex. The IR spectra of the samples after arsenic adsorption exhibited slight decrease in the absorbance peaks at $1793 \mathrm{~cm}^{-1}$ and 1886 $\mathrm{cm}^{-1}$ relative to the iron oxide/hydroxide before arsenic adsorption, which was also associated with co-precipitation process of arsenic on the surfaces of iron oxide/hydroxide (Carabante et al., 2009). Compared to the iron oxide/hydroxide before arsenic adsorption, the Fe-OH of the coating layer in Column IV had a red shift from the absorbance band of $3120 \mathrm{~cm}^{-1}$ to $3097 \mathrm{~cm}^{-1}$. This may be due to the formation of As-O-H bond, which caused a change in the $\mathrm{O}-\mathrm{H}$ vibrational mode and 
decreased the vibration frequency of the O-H bond (Wang and Mulligan, 2008). These pieces of evidence demonstrated that arsenic and iron likely bonded as a bidentate binuclear complex in Column IV (Fig.6b, second case). Waychunas et al. (1993) found, by EXAFS, that the adsorption of $\mathrm{As}(\mathrm{V})$ on poorly crystalline iron oxide/hydroxide was mainly achieved by the formation of bidentate binuclear complexes although the monodentate mononuclear complex adsorption mode also existed. Carabante et al. (2009) revealed that the inner spherical type of bidentate binuclear complexes was more thermodynamically stable, which was the major type of binding between arsenic and the surface of the poorly crystalline iron oxide/hydroxide. In addition, through Fourier transformation infrared spectroscopy studies of bidentate binuclear complexes, Sun et al. (1996) and Lumsdon et al. (1984) found that arsenic imitated this complex reaction by forming arsenic complexes between the surface of the iron oxide/hydroxide and the hydroxyl group. Moreover, Gräfe et al. (2004) showed that when As(V) concentration was high, As(V) could be removed from the aqueous phase through precipitation on the iron oxide/hydroxide surface.

\section{Conclusions}

In this study, the preparation of in situ arsenic removal materials and the arsenic removal process under different conditions were investigated using various quartz sand filled columns to explore an in situ high-arsenic groundwater remediation technology. The mechanism of arsenic removal from the iron coating columns was also discussed. The following can be concluded:

1. A 4-step alternative cycle method was developed, in which $5.0 \mathrm{mmol} / \mathrm{L}$ $\mathrm{FeSO}_{4}$, oxygen-free deionized water and $2.5 \mathrm{mmol} / \mathrm{L} \mathrm{NaClO}$ were alternatively 
injected into the column, and a $96 \mathrm{~h}$ uploading time was used to form the uniform coating of scaly crystalline goethite on the surface of the quartz sand without clogging the columns.

2. The complete breakthrough time of $\mathrm{Na}_{2} \mathrm{HAsO}_{4}$ in the iron-coated quartz sand column was approximately $35 \mathrm{~h}$, much longer than that of tracer fluorescein sodium (approximately $2 \mathrm{~h}$ ). The retardation factor of arsenic was 23.0, and the dynamic adsorption capacity of arsenic was $0.11 \mathrm{~mol} \mathrm{As} / \mathrm{mol} \mathrm{Fe}$. The fixation of arsenic was mainly controlled by chemical adsorption, in which arsenic and iron likely formed monodentate mononuclear complexes on the iron mineral surfaces.

3. In situ arsenic removal in the aquifer was simulated by simultaneous injections of $\mathrm{As}(\mathrm{V})$ and $\mathrm{Fe}(\mathrm{II})$ reagents. The arsenic in the aqueous phase was completely removed by the prepared materials with an arsenic adsorption of $0.05 \mathrm{~mol} \mathrm{As} / \mathrm{mol} \mathrm{Fe}$. The arsenic fixation occurred through a process of adsorption/co-precipitation, in which arsenic and iron may have formed arsenic-bearing goethite phase with small size, by way of bidentate binuclear complexes. The high arsenic removal efficiency likely resulted from the expanded specific surface area of the small goethite particles, which enhanced arsenic sorption capability and/or from co-precipitation of arsenic onto the surface of goethite particles.

\section{Acknowledgement:}

The authors would like to thank the anonymous reviewers for their constructive suggestions and comments on this manuscript. This research was financially supported by the Ministry of Science and Technology of China (2012AA062602), the National Natural Science Foundation of China (Nos.41202168 and 41372254), the 
Center of Hydrogeology and Environmental Survey, CGS (12120113103700) and the Fundamental Research Fund for National Universities, China University of Geosciences (Wuhan). 


\section{Reference}

Agency, U.E.P., 2000. Technologies and Costs for Removal of Arsenic from Drinking Water. Washington, DC.

Appelo, C.A.J. and de Vet, W.W.J.M., 2003. Modeling in situ iron removal from groundwater with trace elements such as As. In: Welch, A.H., Stollenwerk, K.G. (Eds.), Arsenic in Groundwater. Kluwer Academic, Boston.

Appelo, C.A.J., Drijver, B., Hekkenberg, R. and de Jonge, M., 1999. Modeling in situ iron removal from ground water. Ground Water, 37(6): 811-817.

Bordoloi, S., Nath, S.K., Gogoi, S. and Dutta, R.K., 2013. Arsenic and iron removal from groundwater by oxidation-coagulation at optimized $\mathrm{pH}$ : Laboratory and field studies. Journal of Hazardous Materials, 260: 618-626.

Bligh, M.W., Waite, T.D., 2011. Formation, reactivity, and aging of ferric oxide particles formed from $\mathrm{Fe}(\mathrm{II})$ and $\mathrm{Fe}(\mathrm{III})$ sources: Implications for iron bioavailability in the marine environment. Geochim. Cosmochim. Acta, 75(24): 7741-7758.

Carabante, I., Grahn, M., Holmgren, A., Kumpiene, J. and Hedlund, J., 2009. Adsorption of As (V) on iron oxide nanoparticle films studied by in situ ATR-FTIR spectroscopy. Colloids and Surfaces a-Physicochemical and Engineering Aspects, 346(1-3): 106-113.

Cornell, R.M. and Schwertmann, U., 2003. The iron oxides: structure, properties, reactions, occurrences and uses. Weily-VCH. 
Dixit, S. and Hering, J.G., 2003. Comparison of arsenic(V) and arsenic(III) sorption onto iron oxide minerals: Implications for arsenic mobility. Environmental Science \& Technology, 37(18): 4182-4189.

Duker, A.A., Carranza, E.J.M. and Hale, M., 2005. Arsenic geochemistry and health. Environment International, 31(5): 631-641.

Giles, D.E., Mohapatra, M., Issa, T.B., Anand, S. and Singh, P., 2011. Iron and aluminium based adsorption strategies for removing arsenic from water. Journal of Environmental Management, 92(12): 3011-3022.

Grafe, M., Nachtegaal, M. and Sparks, D.L., 2004. Formation of metal-arsenate precipitates at the goethite-water interface. Environmental Science \& Technology, 38(24): 6561-6570.

Grossl, P.R., Eick, M., Sparks, D.L., Goldberg, S. and Ainsworth, C.C., 1997. Arsenate and chromate retention mechanisms on goethite .2. Kinetic evaluation using a pressure-jump relaxation technology. Environmental Science \& Technology, 31(2): 321-326.

Guo, H.M., Wen, D.G., Liu, Z.Y., Jia, Y.F. and Guo, Q., 2014. A review of high arsenic groundwater in Mainland and Taiwan, China: Distribution, characteristics and geochemical processes. Applied Geochemistry, 41: 196-217. 
Jia, Y.F. and Demopoulos, G.P., 2005. Adsorption of arsenate onto ferrihydrite from aqueous solution: Influence of media (sulfate vs nitrate), added gypsum, and pH alteration. Environmental Science \& Technology, 39(24): 9523-9527.

Jiang, W. et al., 2013. Arsenate and cadmium co-adsorption and co-precipitation on goethite. Journal of Hazardous Materials, 262: 55-63.

Kanel, S.R., Greneche, J.M. and Choi, H., 2006. Arsenic(V) removal kom groundwater using nano scale zero-valent iron as a colloidal reactive barrier material. Environmental Science \& Technology, 40(6): 2045-2050.

Keimowitz, A.R. et al., 2007. Laboratory investigations of enhanced sulfate reduction as a groundwater arsenic remediation strategy. Environmental Science \& Technology, 41(19): 6718-6724.

Korngold, E., Belayev, N. and Aronov, L., 2001. Removal of arsenic from drinking water by anion exchangers. Desalination, 141(1): 81-84.

Lee, Y., Um, I.H. and Yoon, J., 2003. Arsenic(III) oxidation by iron(VI) (ferrate) and subsequent removal of arsenic(V) by iron(III) coagulation. Environmental Science \& Technology, 37(24): 5750-5756.

Loring, J.S., Sandstrom, M.H., Noren, K. and Persson, P., 2009. Rethinking Arsenate Coordination at the Surface of Goethite. Chemistry-a European Journal, 15(20): 5063-5072. 
Lumsdon, D.G., Fraser, A.R., Russell, J.D. and Livesey, N.T., 1984. New Infrared Band Assignments for the Arsenate Ion Adsorbed on Synthetic Goethite (Alpha-Feooh). Journal of Soil Science, 35(3): 381-386.

Mettler, S. and Von Gunten, U., 2002. Reactivity of Fe(II) in presence of calcite and Fe/CaCO3 solid-solution. Geochimica Et Cosmochimica Acta, 66(15A): A509-A509.

Miller, G.P., 2006. Subsurface Treatment for Arsenic Removal. American Water Works Association Research Foundation, Denver.

Mishra, D. and Farrell, J., 2005. Evaluation of mixed valent iron oxides as reactive adsorbents for arsenic removal. Environmental Science \& Technology, 39(24): 9689-9694.

Mohan, D. and Pittman, C.U., 2007. Arsenic removal from water/wastewater using adsorbents - A critical review. Journal of Hazardous Materials, 142(1-2): 1-53.

Mondal, P., Majumder, C.B. and Mohanty, B., 2006. Laboratory based approaches for arsenic remediation from contaminated water: Recent developments. Journal of Hazardous Materials, 137(1): 464-479.

Mondal, P., Bhowmick, S., Chatterjee, D., Figoli, A., Van der Bruggen, B., 2013. Remediation of inorganic arsenic in groundwater for safe water supply: A critical assessment of technological solutions. Chemosphere, 92(2): 157-170.

Nordstrom, D.K., 2002. Public health - Worldwide occurrences of arsenic in ground water. Science, 296(5576): 2143-2145. 
Raven, K.P., Jain, A. and Loeppert, R.H., 1998. Arsenite and arsenate adsorption on ferrihydrite: Kinetics, equilibrium, and adsorption envelopes. Environmental Science \& Technology, 32(3): 344-349.

Ravenscroft, P., Brammer, H. and Richards, K., 2009. Alobal sythesis. Arsenic Pollution. Wiley-Blackwell.

Regenspurg, S., Peiffer, S., 2005. Arsenate and chromate incorporation in schwertmannite. Applied Geochemistry, 20(6): 1226-1239.

Richmond, W.R., Loan, M., Morton, J. and Parkinson, G.M., 2004. Arsenic removal from aqueous solution via ferrihydrite crystallization control. Environmental Science \& Technology, 38(8): 2368-2372.

Rott, R. and Friedle, M., 1985. Physical, chemical and biological aspects of the removal of iron and manganese underground. Water Science and Technology: Water Supply (3): 143-150.

Rott, U., Meyer, C. and Friedle, M., 2002. Residue-free removal of arsenic, iron, manganese and ammonia from groundwater. Innovations in Conventional and Advanced Water Treatment Processes, 2(1): 17-24.

Sarkar, A.R. and Rahman, O.T., 2001. In-situ removal of arsenic - experiences of DPHE-Danida pilot project. Technologies for Arsenic Removal From Drinking Water. Technologies for Arsenic Removal From Drinking Water. 
Bangladesh University of Engineering and Technology and The United Nations University, Bangladesh.

Shan, H.M. et al., 2013. A cost-effective system for in-situ geological arsenic adsorption from groundwater. Journal of Contaminant Hydrology, 154: 1-9.

Shih, M.C., 2005. An overview of arsenic removal by pressure-driven membrane processes. Desalination, 172(1): 85-97.

Smedley, P.L. and Kinniburgh, D.G., 2002. A review of the source, behaviour and distribution of arsenic in natural waters. Applied Geochemistry, 17(5): $517-568$.

Stanforth, R. and Zhao, H.S., 2001. Competitive adsorption of phosphate and arsenate on goethite. Abstracts of Papers of the American Chemical Society, 221: U335-U335.

Sun, X.H. and Doner, H.E., 1996. An investigation of arsenate and arsenite bonding structures on goethite by FTIR. Soil Science, 161(12): 865-872.

Taylor, K.G., Konhauser, K.O., 2011. Iron in Earth surface systems: A major player in chemical and biological processes. Elements, 7(2): 83-88.

Tokoro, C., Yatsugi, Y., Koga, H. and Owada, S., 2010. Sorption Mechanisms of Arsenate during Coprecipitation with Ferrihydrite in Aqueous Solution. Environmental Science \& Technology, 44(2): 638-643. 
van Halem, D., Heijman, S.G.J., Amy, G.L. and van Dijk, J.C., 2009. Subsurface arsenic removal for small-scale application in developing countries. Desalination, 248(1-3): 241-248.

van Halem, D. et al., 2010. Subsurface iron and arsenic removal: low-cost technology for community-based water supply in Bangladesh. Water Science and Technology, 62(11): 2702-2709.

Voegelin, A. and Hug, S.J., 2003. Catalyzed oxidation of arsenic(III) by hydrogen peroxide on the surface of ferrihydrite: An in situ ATR-FTIR study. Environmental Science \& Technology, 37(5): 972-978.

Wang, S.L. and Mulligan, C.N., 2008. Speciation and surface structure of inorganic arsenic in solid phases: A review. Environment International, 34(6): 867-879.

Waychunas, G.A., Rea, B.A., Fuller, C.C. and Davis, J.A., 1993. Surface-Chemistry of Ferrihydrite .1. Exafs Studies of the Geometry of Coprecipitated and Adsorbed Arsenate. Geochimica Et Cosmochimica Acta, 57(10): 2251-2269.

Welch, A.H., Stollenwerk, K.G., Paul, A.P., Maurer, D.K. and Halford, K.J., 2008. In situ arsenic removal in an alkaline elastic aquifer. Applied Geochemistry, 23(8): 2477-2495.

WHO, 2011. Guideline for Drinking-Water Quality, 4th ed. World Health Organization. Geneva, Switzerland, 564. 
Xie, X.J. et al., 2009. Geochemistry of redox-sensitive elements and sulfur isotopes in the high arsenic groundwater system of Datong Basin, China. Science of the Total Environment, 407(12): 3823-3835.

Xie, X.J. et al., 2008. Arsenic mobilization in shallow aquifers of Datong Basin: Hydrochemical and mineralogical evidences. Journal of Geochemical Exploration, 98(3): 107-115.

Zhao, H.S. and Stanforth, R., 2001. Competitive adsorption of phosphate and arsenate on goethite. Environmental Science \& Technology, 35(24): 4753-4757. 


\section{Figure Captions:}

Figure 1 Schematic figure of the experimental column set-up.

Figure 2 The breakthrough curve for fluorescein sodium (a) and $\mathrm{Na}_{2} \mathrm{HAsO}_{4}$ (b)

Figure 3 Scanning electron microscopy (SEM) image and energy dispersive X-ray spectrum (EDS) of Fe-coating quartz sand before and after As loading. (a)- SEM image before As loading; (b)- EDS energy spectrum before As loading; (c)- SEM image after As loading; (d)- EDS spectrum after As loading.

Figure 4 The electron microscopy image of Fe-coated quartz grains and the EDS energy spectrum before and after As loading by electron microprobe.

Figure 5 The infrared spectra results for column I before and after As loading.

Figure 6 The three mainly bonded manner of $-\mathrm{OH}$ on the iron oxides/hydroxides surface (a); The mainly bonded manner of $\mathrm{As}(\mathrm{V})$ onto the surface of the iron oxides/hydroxide.

Figure 7 The comparison of the SEM image for column I (a), III (b) and IV(c) and the EDS energy spectrum for the spot in (c)

Figure 8 The comparison of the infrared spectra results for column I (a), III (b) and $\operatorname{IV}(c)$. 


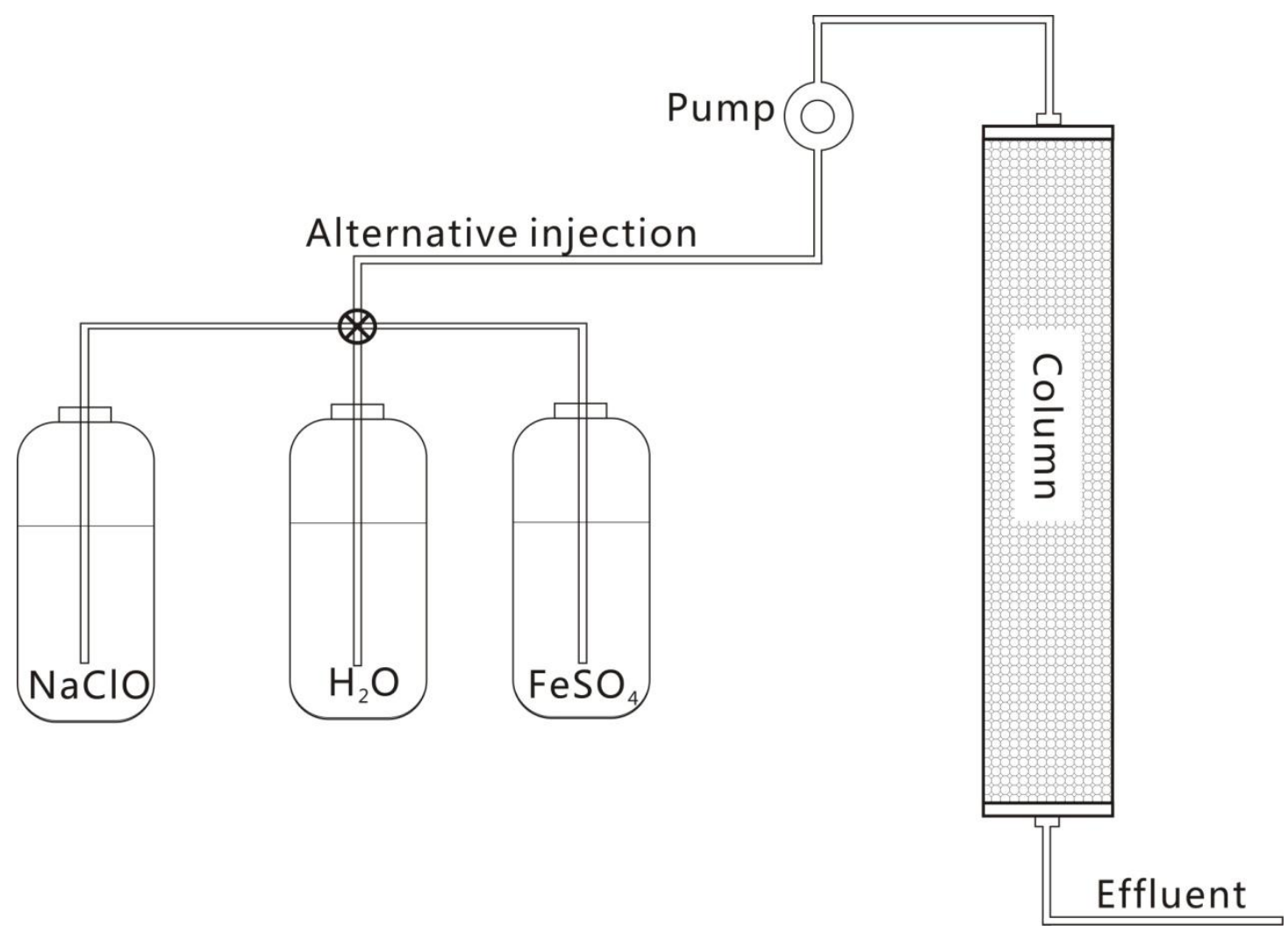

Figure 1 

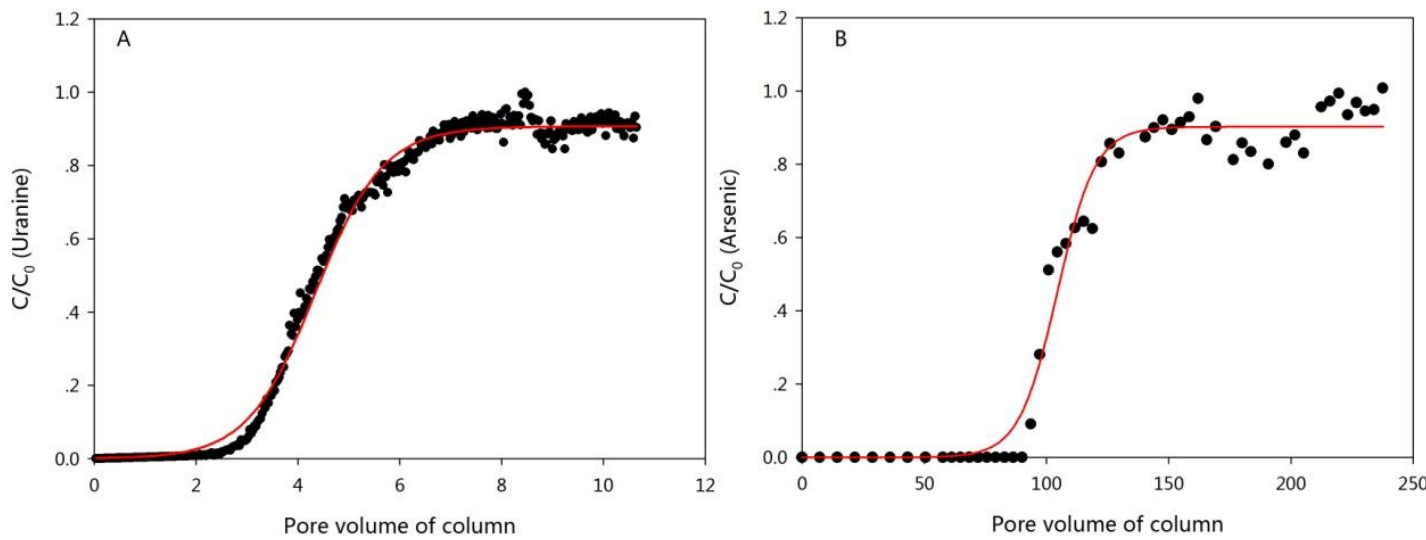

Figure 2 

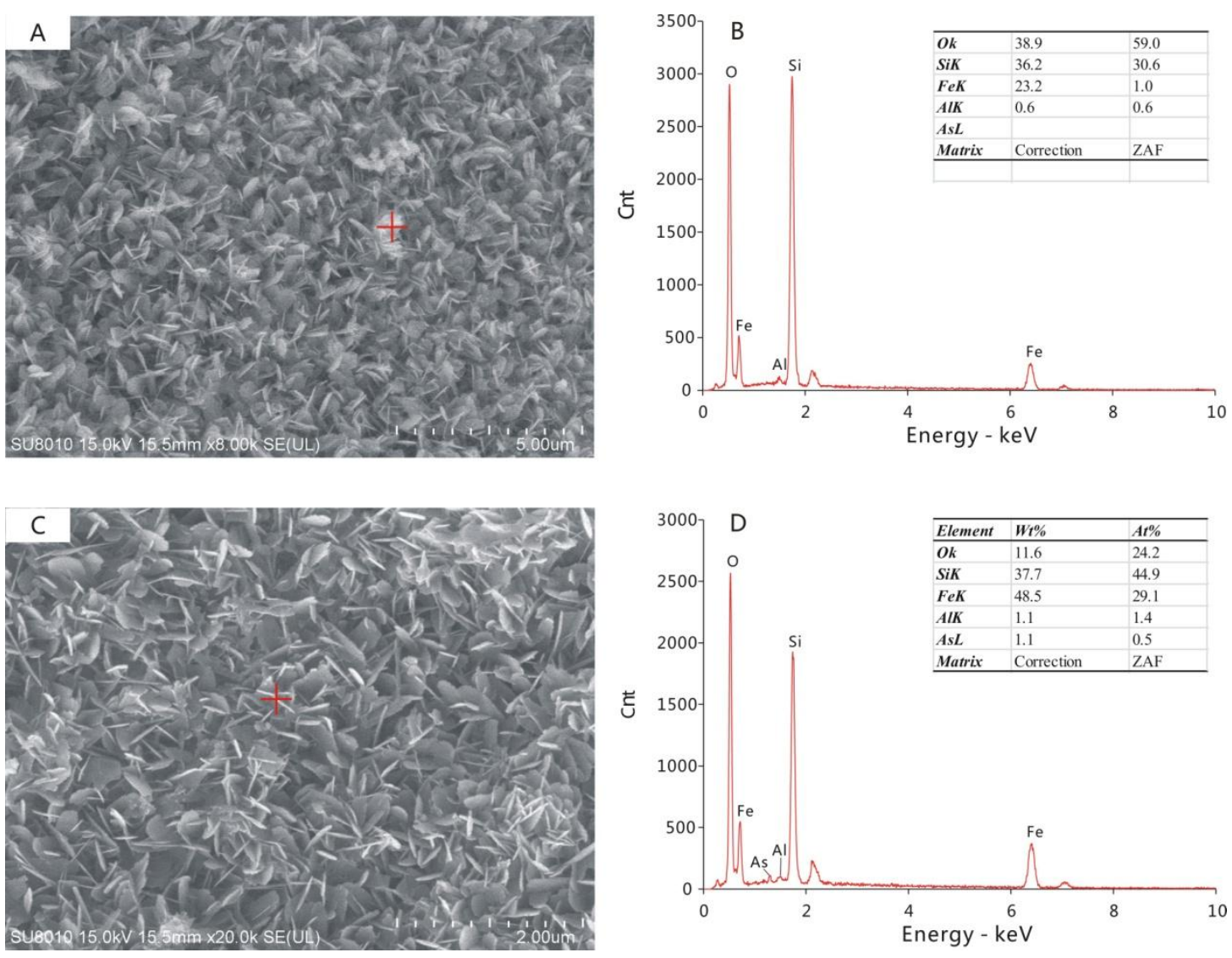

Figure 3 

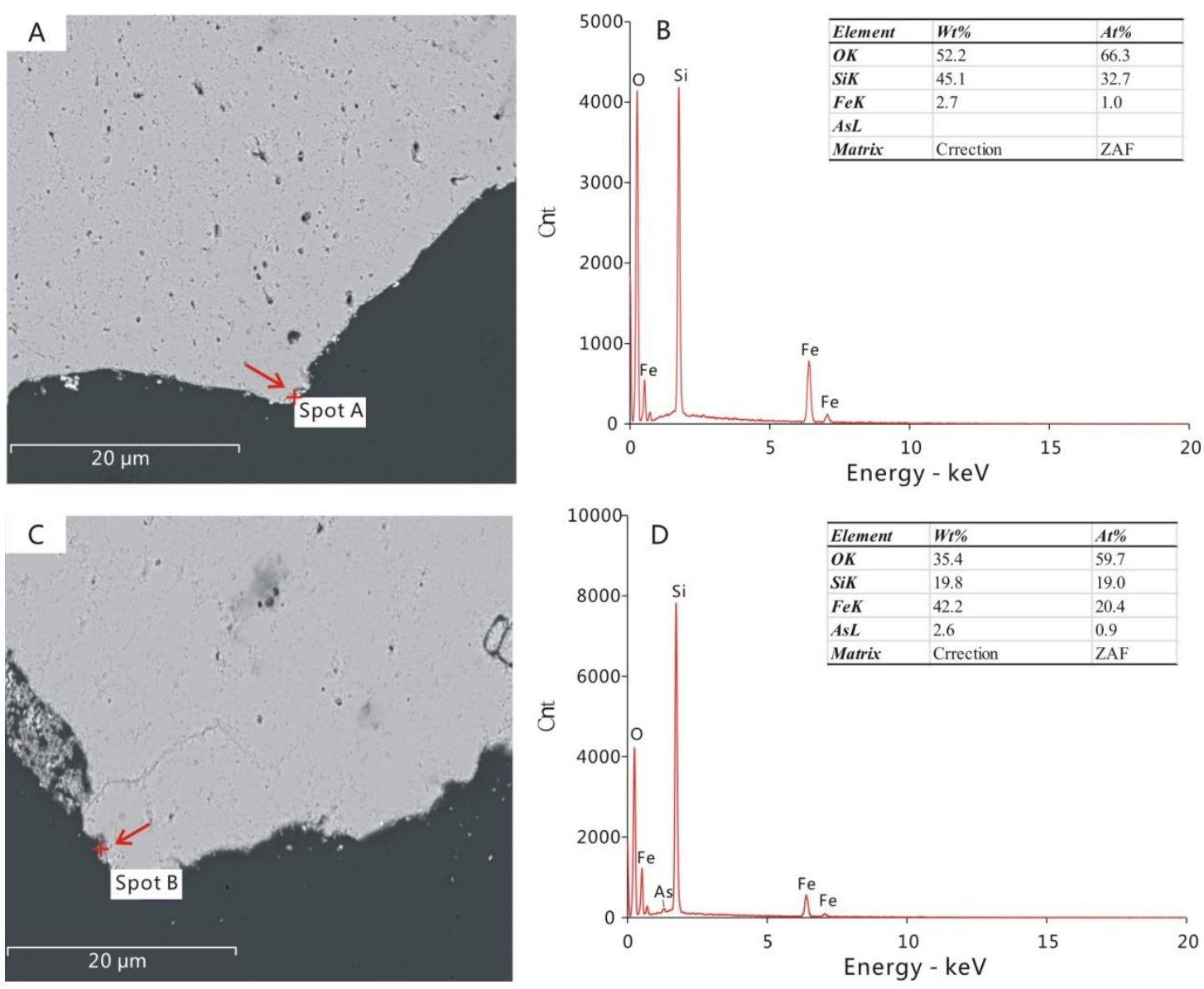

Figure 4 


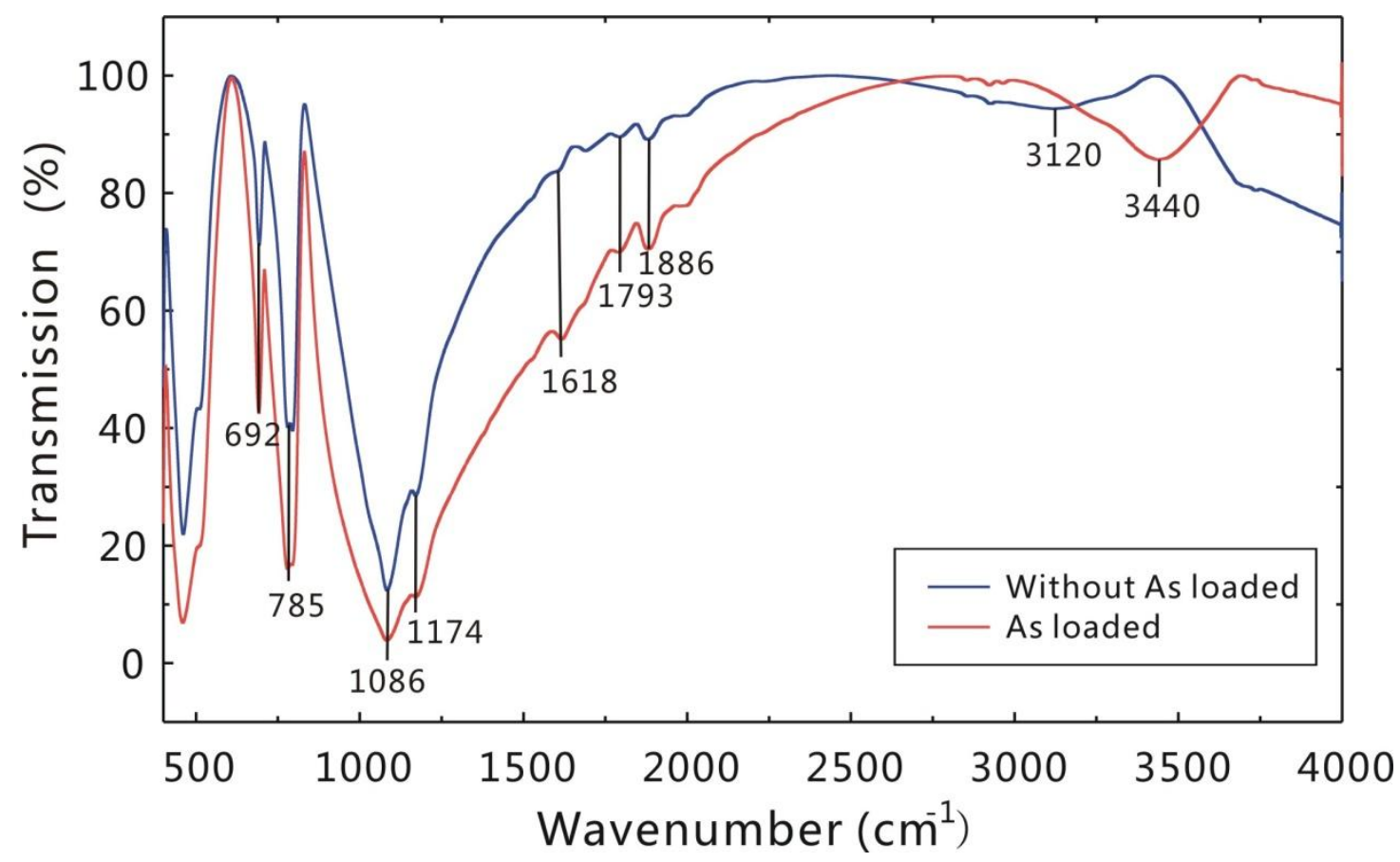

Figure 5 
(a)

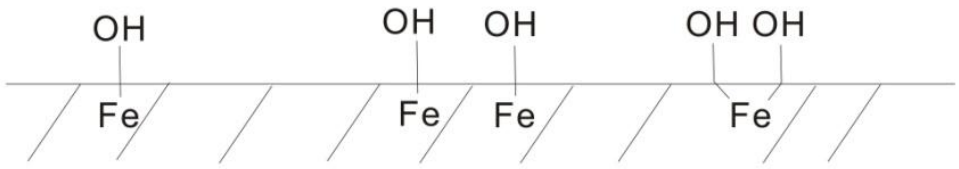

(b)

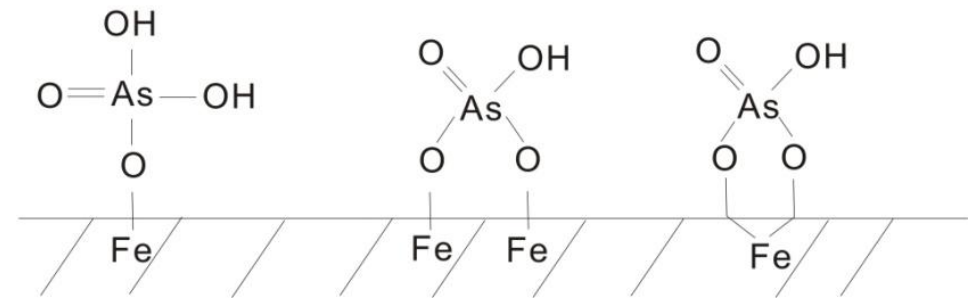

Figure 6 

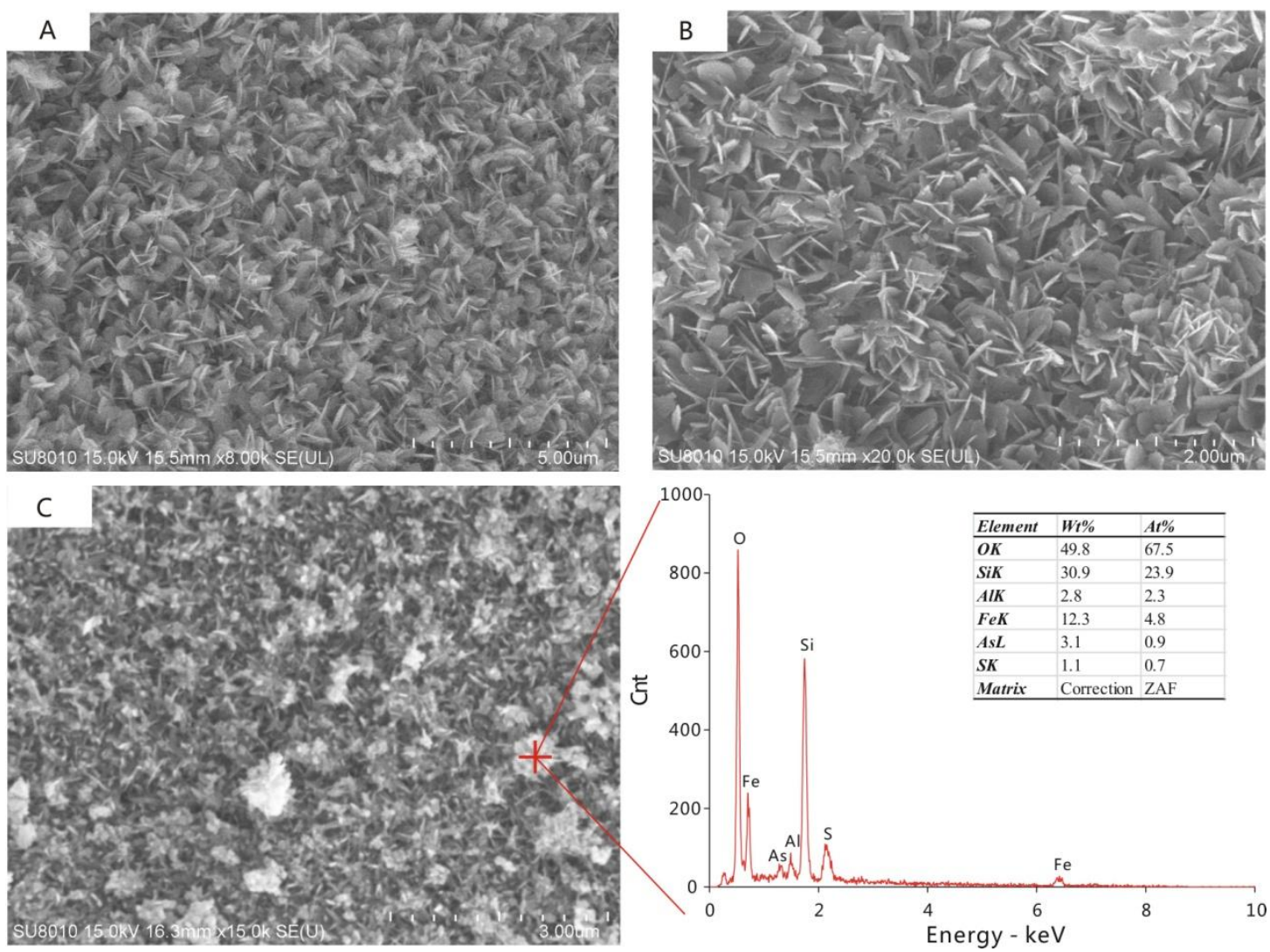

Figure 7 


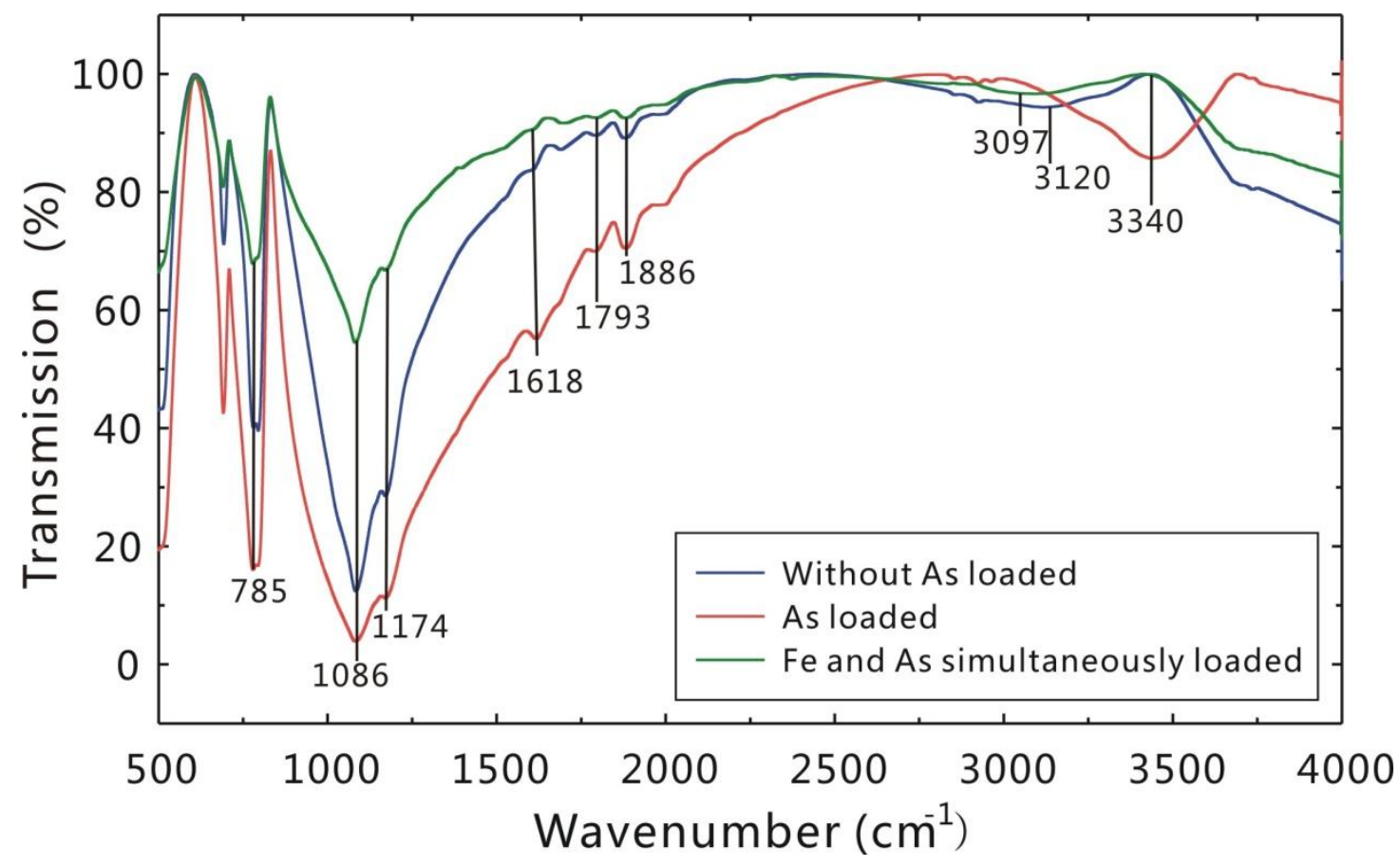

Figure 8 